Paper ID \#18306

\title{
The Development of Engineering Management Education in K-12 Schools: A Longitudinal Case Study
}

\section{Dr. Andrew J. Czuchry, East Tennessee State University}

Andrew Czuchry received his Ph.D. from the University of Connecticut in 1969 with a concentration in guidance and control systems engineering. He has more than twenty years experience as a professional manager in technical innovation and the electronics manufacturing industry. Dr. Czuchry is a tenured full professor and has been the holder of the AFG Industries Chair of Excellence in Business and Technology since joining East Tennessee State University in 1992. He has more than 100 co-authored articles that have appeared in refereed journals and proceedings of professional organizations related to his field.

\section{Dr. James H. Lampley, East Tennessee State University}

Dr. Lampley received his Ed.D. from East Tennessee State University and currently serves as an Assistant Professor and Research Specialist in the Educational Leadership and Policy Analysis Department at ETSU. Dr. Lampley has been an ELPA faculty member since 2004. As a Research Specialist he works with dissertation students on quantitative research topics. Dr. Lampley also serves as the Graduate Program Coordinator for the Post Secondary and Private Sector Leadership concentration in the ELPA department. Dr. Lampley teaches a variety of courses including Research Methods, Educational Statistics, and Quantitative Analysis. Currently, Dr. Lampley has research interests in online delivery and graduate education and spearheads research opportunities as often as possible.

\section{Mr. Addison Scott Karnes, East Tennessee State University}

B.S. in Engineering Technology M.S. in Technology Doctoral Fellow Dissertation Candidate

\section{Mr. Leendert Menist Craig, East Tennessee State University}

Leendert Craig graduated from East Tennessee State University (ETSU) with a Masters in Engineering Technology in 2015. While working on his masters he worked as a graduate assistant in the Department of Engineering Technology, Surveying and Digital Media. He also earned his B.S. in Product Development Engineering Technology at ETSU in 2013. Mr. Craig also has held a Master Plumber License as well as a natural gas license since the early 1980's. He owned and operated Lenny's Plumbing and Water Treatment in the 1980's and 1990's. He currently works in the Educational Leadership and Policy Analysis department at ETSU as a doctoral fellow while pursuing his Ed.D. in Private Sector Educational Leadership. 


\title{
The Development of Engineering Management Education in K-12 Schools: A Longitudinal Case Study
}

\begin{abstract}
In partnership with Bristol Tennessee Essential Services (BTES) whose economic development initiatives provided fiber optic internet to local schools, an engagement agreement was drafted in which an ETSU graduate student team was contracted to develop an improved delivery methodology. This article presents a longitudinal case study and underscores the implications for engineering management education.

\section{Background/Introduction}

Reference is made to a 2016 ASEE Conference publication: Strategic Alliances May Become Key Success Factors for Enhanced Experiential Learning: A Conceptual Framework for Implementation. ${ }^{1}$ Building upon the successful strategic alliance formed in 2014 with the mayors of Sullivan and Washington counties in East Tennessee, a common Workforce Readiness challenge to economic development was addressed. Both mayors had received complaints from local businesses that graduating students did not possess the professional development skills required for employment and vital to the growth of existing businesses throughout the region served by our university. As part of the eight county Workforce Readiness Program Sullivan County (Tennessee) volunteered to pilot the ACT National Career Readiness Certificate which awards readiness level indicators based on performance on their WorkKeys assessment. ${ }^{2}$ This article deployed the framework for experiential learning cited above and extends the scope of the Workforce Readiness to Engineering Management education in K-12 schools.
\end{abstract}

In an engineering organization, a functional manager must execute these five essential tasks: 1) Planning; 2) Organizing; 3) Staffing; 4) Directing and 5) Controlling. A living laboratory becomes a proving ground where engineers with managerial responsibilities are given realworld problem solving opportunities where a blending of leadership and management skills is necessary to address conflicting problem solving cultures and/or when combined business and technology solutions are necessary. In exciting entrepreneurial organizations, these opportunities occur on a routine basis. However, in a large organization, sufficient agility is often blocked by risk aversion and technical arrogance. Greenleaf's text on Servant Leadership and/or scripture are often suggested as required reading. ${ }^{3}$

\section{Current Study}

The current article provides an example of experiential learning and shows the use of Christensen's disruptions caused by the use of existing technology. ${ }^{4}$ The research team believes that in addition to illustrating the experiential learning sub-process, there are several other specific impacts that the ASEE Conference attendees may find helpful. These are discussed briefly below.

Strategic planning: a two-step process: Define strategies to sustain a competitive advantage in today's global business environment and then develop action plans to deploy strategies. Most often this step identifies core competencies, strategic advantages, and challenges. Leaders 
define the vision, guiding principles, values, establish priorities, and commit resources to achieve desired results. Managers have the functional responsibility of organizing and ensuring technical excellence in mission critical technologies while improving internal/operational efficiencies to accomplish the organization's mission.

\section{$\underline{\text { Staffing }}$}

Managers hire the necessary talent and train, develop, and assess performance of the workforce necessary to implement the action plans established in the strategic plan while ensuring that technical excellence is maintained for their technology center (core competency).

\section{Directing}

Managers traditionally get work done through others; leaders inspire the workforce to take action to achieve extraordinary goals. When innovation is essential to maintain competitive advantage, managers often argue that attitude is often more important than skills. Management says we hire for attitude and train for skills because hard work will beat talent when talent does not work hard enough. But what if the talented also work hard? Leadership is essential in attracting talent and motivating hard working, creative problem-solving teams. Leadership also engages customers to create a semi-open approach to innovation establishing verifiable trust and ensuring agility while incrementally implementing evolutionary change to the organization's DNA. Systematic artistic change preserves gains from what has worked in the past while migrating to the semi-open system of the future offering one potential highway to success.

\section{Controlling}

One thing remains true today: If something is to be controlled, the outcome must be measurable. When systems and problems can be approximated by linear systems and linear analyses, management is fine. By "linear systems" it is meant that superposition applies, correlation is linked to root cause and effects, the Central Limit Theorem applies, and $\mathrm{y}=\mathrm{mx}+\mathrm{b}$.

However, in technology driven businesses, this is rarely the case; statistical analysis alone is never sufficient. Combined technology and business problems require combined, innovative, non-linear solutions, and calculus of variation/complex two-point boundary value problems has highly sensitive adjoint variables. Hence, strong technical and marketing non-linear problemsolving skills are essential to success. Leadership is vital, and well-managed, Small to Medium Size Enterprises (SMEs) lacking such hard-working leadership talent may have a going-out-ofbusiness plan.

Visionary Leadership may not be teachable, however, given the essential attributes, leadership can be enhanced. Leadership requires good judgment, but good judgment comes from experience. This experience often provides the most impact when bad judgment has occurred. This is the fundamental argument for experiential learning in what this team calls living laboratories. 
One way of examining the program's leadership requirements is to view leadership development as a lifelong process. Then, formal knowledge acquisition is a reasonable starting point. Mutually beneficial partnerships between higher education and the communities served offer excellent opportunities for experiential learning. Hopefully, this article will shed some light on a path that others may choose to follow.

Experiential learning can be applied when teaching the entrepreneurial thought process by converting theory into reality. At East Tennessee State University, a course was developed that teaches experiential learning by combining business and engineering technology students into teams. The students utilize engineering management techniques to solve real-world problems facing K-12 education in an attempt to improve the K-12 students' learning outcomes. ETSU graduate students learn how to problem-solve in non-linear situations. One of the biggest challenges in teaching a class such as this is finding real-world projects that are sufficiently meaningful to qualify as graduate level work and may be accomplished in a 16-week semester.

During one such class, a local mayor shared a real-world problem with which his county was struggling: the high cost of laying fiber through the difficult, mountainous terrain of East Tennessee to all the schools in the county. The mayor wanted to enable teachers to share resources and interact with multiple classrooms at different schools without requiring colocation. The county hired several consulting firms that all reached the same conclusion: high speed internet would require fiber installation at all facilities. The estimated \$200 million cost was prohibitive.

A graduate student team at ETSU recommended the repurposing of existing technologies (Amateur Radio and Amateur Television) which would solve the mayor's problem at a fraction of the cost. The mountainous terrain became an asset instead of an obstacle. This is an example of utilizing disruptive innovation: taking an existing technology and using it in a nonconventional way to solve a new problem ${ }^{4}$. These older technologies still permit two-way audio and video as well as data transmission at less than one tenth percent of the cost $(\$ 200,000$ instead of \$200 million). Because no special equipment was required other than a television for reception, homeschooled students could also participate in the live classes. Teachers and students from different schools could interact, ask questions, and access the internet. This solution satisfied the requirements the mayor had outlined for the team, and demonstrated the use of engineering management principles and disruptive innovation.

The mayor was very excited because these technologies could also be used to teach the applications of the STEM curriculum. As part of the student team's final presentation, the mayor invited several of the board members along to decide if this was a plan that they could embrace. Unfortunately, a non-linear problem arose in the form of an unanticipated requirement: security. The team was unaware of the school system's need for private data storage. This proved to be a key part of the experiential learning process for everyone involved. This experience illuminated the importance of having a full set of requirements at the onset.

This was not a wasted effort. The mayor learned that by removing the constraints, other options became feasible. The mayor learned to look for answers to challenges that are presented by first eliminating the constraints and considering what solutions are now possible. "In our reality, any 
system has very few constraints." 5 To find the right solution, the problem must be correctly defined.

The student team redefined the problem and created a new web portal that better addressed the needs of the students. This new solution showed so much potential that a mayor from a second county joined in support of the project.

The mayors realized that they were both trying to solve the same problem. Northeast Tennessee also faces a technology gap. A large part of the problem was the wide variability of internet service available to the students in the two counties ranging from no internet service at all to one megabit per second depending on location. This was the first time in many years that the mayors of these two counties had been actively working together on a joint project.

The student team's solution addresses a problem that exists in the workforce in East Tennessee. K-12 students are graduating without a strong set of professional development skills. These skills are vital to the growth of business in the region served by ETSU. The web portal developed by the student team addressed these shortcomings. One of the mayors also invited mayors from six more counties and several cities to become involved with this project because they recognized the future economic development potential.

As part of this eight county Workforce Readiness initiative, Sullivan County (Tennessee) volunteered to pilot the ACT WorkKeys assessment in two of its high schools wherein the students had the opportunity to earn the ACT National Career Readiness Certificate (NCRC). This certificate is nationally recognized as a professional development credential by over 10,000 employers. ACT WorkKeys assessment also awards competency-based work readiness level indicators that provide these 10,000+ employers with a standardized metric for professional development skills in Applied Mathematics, Reading for Information, and Locating Information.

As part of the partnership effort with BTES the ETSU college graduate consulting team was contracted to develop an improved delivery methodology for the highly successful approach in use at Sullivan East and Sullivan Central high schools. One measure of this program's success was realized when 18 graduating high school seniors simultaneously received their two-year Associate Degrees from Northeast State Community College through their dual enrollment program. ${ }^{6}$

The challenge given to the cross-functional consulting team was to broaden the scope to all Career Technology Education (CTE) students throughout Sullivan County. The college graduate student team developed a hybrid software/hardware fiber optic private cloud data management network that simultaneously protects sensitive, mission-critical information and locally hosts a user-friendly workforce development on-line classroom tailored to specific opportunities for student improvement.

The consulting team began by interviewing graduating seniors who had recently taken the WorkKeys assessment. They expressed their frustrations with finding specific lessons buried amongst thousands of pages across nearly two-dozen PDFs with no indices or tables of contents. This required the students to open each PDF in order and scroll through every page until finally 
identifying the desired lesson. This was an extremely time-consuming process for the students especially those without high-speed internet access at home.

Rather than immediately seeking a solution, the team was instructed to first conduct benchmarking research of best practices in online educational and professional development resources. ${ }^{7}$ Through benchmarking studies, the students learn important engineering management concepts such as how to avoid re-inventing the wheel and how to use existing technology in innovative ways.

\section{Results}

The team concluded that each of the "best" online training resources had its strengths and weaknesses. Their solution was to construct a web portal that consolidated and organized the information taught in these PDFs and supplemented this material with the "all-star team" of lessons from several open source, online training resources. The portal also had an embedded page featuring WorkKeys practice assessments, itemized scoring, customized lesson plans, and additional study resources.

Also, embedded in the portal were professional development resources featuring a national database of NCRC employers, job postings with readiness level requirements, and employment profile tools. Through the portal, users could access individual learning style assessments that offer study tips and recommendations of resource media that may be more effective for each user's learning style(s). Provisions were made to include online classroom functionality wherein teachers could create and upload custom content on a private class page.

The graduate team used lateral thinking to provide a nonlinear solution in the form of a disruptive innovation using existing technology. ${ }^{8}$ Building upon the strategic alliance formed during the previous project, the team learned the importance of protecting private student information. Therefore, any proposed solution to the mayors' common workforce development problem had to also emphasize cyber security.

The engineering management problem solving techniques our students learn have applications outside of the classroom. Defining a problem and being confident it is defined completely can save considerable time and resources. Frequently businesses utilize closed loop systems to monitor production. Because innovation often requires "thinking outside the box," the closed loop system can obstruct innovation. Utilizing lateral thinking we can open the system which will allow a greater number of variables into the feedback loop, this can create opportunities that may have been missed. Opening the system will allow innovative ideas to emerge. It can also help determine if the analysis we are reaching in a closed loop system is accurate or not. ${ }^{9}$

\section{Conclusions/Future Work}

As a future requirement, individual user accounts allow teachers and parents to track the students' study habits and progress (via the practice WorkKeys assessments). Students will use this data as a skills development feedback loop. An important engineering management concept the consulting team learned is that this feedback loop is the best metric of study method 
effectiveness (aside from taking the real WorkKeys multiple times). Consequently, this feedback loop mandates the accumulation and analysis of private student information. How can the process be improved? - innovation through incremental improvement. Check Act Plan-Do (CAP Do) - incremental changes are most often implemented at the managerial level. They are best implemented as small changes to the production line for continuous improvement by changing the study methods without creating chaos. ${ }^{10}$

This model was first conceptualized by Shewhart (Plan-Do-Check-Act) and modified by Deming (Plan-Do-Study-Act). ${ }^{11}$ Finally, it was tailored to the manufacturing specific operations by Toyota (Check-Act-Plan-Do: CAP-DO). ${ }^{12}$ Figure 1 illustrates the CAP-DO process and Figure 2 illustrates the Plan-Do-Check-Act process.

\section{Figure 1}

\section{The CAP-D0 Process ${ }^{12}$}

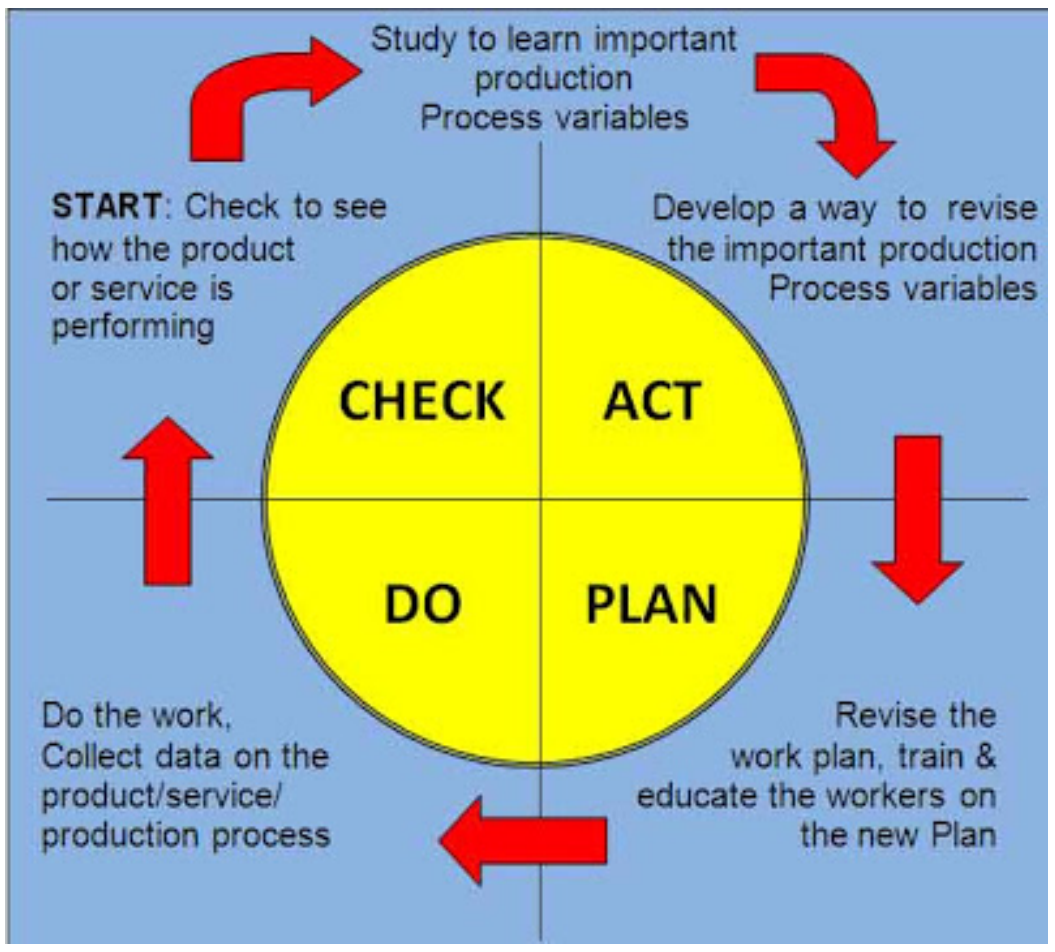

Toyota turned it to identifying a known problem and finding a solution for it can be much more profitable than creating a product and trying to create a market for it, since the market for it will already exist along with pent up demand. This can be a new use for Plan-Do-Check-Act which is normally used when conducting a complete system overhaul. This is best implemented at the engineering management leadership level. These are more radical changes in the system, or a complete system overhaul, and can lead to the introduction of a new product. It can often utilize disruptive innovation techniques. 


\section{Figure 2 \\ The Shewhart Cycle ${ }^{13}$}

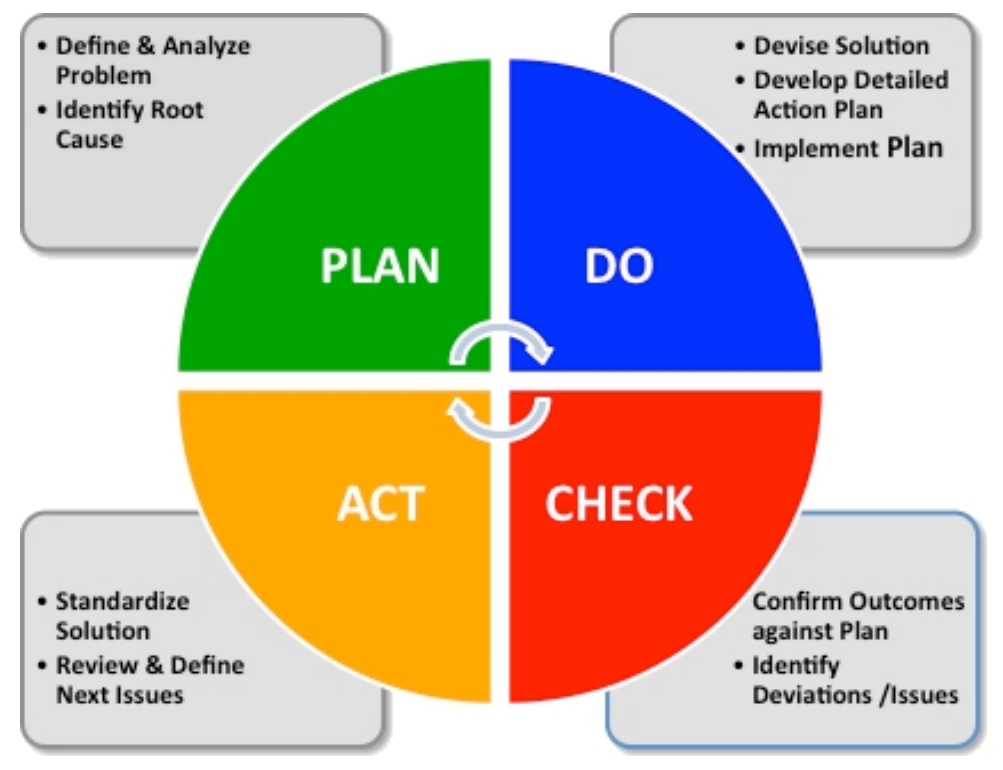

The team's newest strategic alliance with Bristol Tennessee Essential Services created the unique opportunity to solve two of Sullivan County's problems with a single, unifying solution. Working with BTES, the team designed and constructed a private data management cloud utilizing their existing fiber optic network. Private and mission critical information can be securely transmitted between any two nodes on the fiber network through the BTES head end.

For example, a "clean" computer at the school will establish a secure, closed connection via gigabit fiber through the head end to the fortified offsite server nexus. The information will be stored on a series of redundant drives and optical discs. Separate from these backups is another server series that hosts the web portal and performs analytics on the users' profiling data.

The team's innovative solution was embraced enthusiastically by the mayors. It was strategically aligned with both their workforce development and information security goals. Furthermore, the scope of the effort was extended beyond CTE graduating seniors and includes the fundamentals essential for students intending to pursue the BS Engineering Degree as well. Beta testing of the portal was planned as a pilot project to ensure improved workforce readiness for Sullivan County graduating high school seniors’ professional development skills by February 2017, and initial pilot test program quantitative results will be accessible as archival data by May 2017.

This team firmly believes that successful entrepreneurs have a combination of talents. Among these are creative idea generation, innovative practical implementation schemes, and an ability to listen to customers and employees to solve problems that add value others are willing to pay a premium to receive. "The nonlinear nature of the combined business and technology problem causes changes that are beyond the scope of management alone."9 
In the path forward, the goal is to incorporate STEM into the portal. One would first look for any system overlap. Then, the team would execute finding the necessary materials, measure their relevance, and finally change the interface to make the new material available for use.

Experiential learning has been a part of the education process in institutions of education since the beginning - sometimes called an internship or field experience. Some professions may call the experience hands-on learning or real-world projects, and "learning-by-doing" is a phrase often heard in the trades or in technical education.

Regardless of the name, the goal is the same - allow students to gain experience in solving problems. Experiential learning may include all these activities and more. There must be a final component, a self-evaluation by students about what went wrong and what went right in their experiential learning project. This reflective process is what elevates a hands-on experience to experiential learning.

\section{Authors’ Note}

How does this article relate to Engineering Management Education? A special thanks goes out to the reviewers who precipitated this question in a gentle but penetrating way! They gave us renewed confidence in the benefits of the peer review process, and they inspired us to reflect on why we undertook this effort in the first place.

Twenty-five years ago, the lead author made a career change that all but a few thought was insane. Leaving a senior executive position as President of a joint venture between Raytheon and General Dynamics, he joined East Tennessee State University (ETSU) a regional university with a clearly expressed mission: Promote Entrepreneurship (which he could not even spell) by integrating Business and Technology.

When consulting for a group of 13 Vice Presidents at Sprint who were reengineering themselves out of a job, the author was asked an equally penetrating question: "Do you believe in the Peter Principle?" NO, he did not because it is only a statement that expresses the lack of a will to learn! He went on to share how every time he was promoted or changed jobs he found himself grossly incompetent. Either he learned what he needed to know or he would need a new mission statement. And no, that's not why he is in teaching now as one of his better students might say.

${ }^{1}$ Czuchry, A., Lampley, J., Craig, L., Karnes, A. (2016). “Strategic Alliances May Become Key Success Factors for Enhanced Experiential Learning: A Conceptual Framework for Implementation.” Presented at and published in the Proceedings of the 2016 American Society for Engineering Education Annual Conference and Exposition, New Orleans, Louisiana.

${ }^{2}$ ACT Inc. (2017). National Career Readiness Certificate (NCRC). Retrieved January 24, 2017 from https://www.act.org/content/act/en/products-and-services/workforce-solutions/act-nationalcareer-readiness-certificate.html.

${ }^{3}$ Greenleaf, R.K. (1977). Servant Leadership, Paulist Press.

${ }^{4}$ Christensen, C.M. (1997). The Innovator's Dilemma: When New Technologies Cause Great Firms to Fail, Harvard Business School Press, Boston, MA. 
${ }^{5}$ Goldratt, E.M. (1993). "What is the Theory of Constraints?” APICS-The Performance Advantage June. Reprinted in Selected Readings in Constraints Management. Falls Church, VA: APICS. 1996, 3-6.

${ }^{6}$ Wagner, R. (2016). Kingsport Times News. Retrieved January 25, 2017 from http://www.timesnews.net/Education/2016/05/08/Sullivan-has-18-student-graduating-fromNortheast-State-before-high-school.

${ }^{7}$ Kahn Academy. Retrieved January 24, 2017 from https://www.khanacademy.org/. ${ }^{8} \mathrm{de}$ Bono, E., Lateral Thinking: The Toolset of Creativity and Innovation. Retrieved January 24, 2017 from https://www.edwdebono.com/lateral-thinking.

${ }^{9}$ Czuchry, A., Craig, L. and Lampley, J. (2017). "Experiential Learning in Teaching Innovative Engineering Entrepreneurship.” Presented at and published in the Proceedings of the Conference for Industry and Education Collaboration, Jacksonville, Florida.

${ }^{10}$ Tsukuda, R. (2008). The Illustrated Toyota Production System: A Lean Transformation Primer, Gemba Press.

${ }^{11}$ Moen, R. and Norman, C. (2015, May 28). Circling Back: Clearing up Myths about the Deming Cycle and Seeing How it Keeps Evolving. Retrieved March 15, 2017 from http://www.apiweb.org/circling-back.pdf.

${ }^{12}$ Priyo, Y. (2012, January 11). CAP-DO Cycle (Improvement Method for Existing Manufacturing). Retrieved January 19, 2017, from http://5smanagement.com/cap-do-cycleimprovement-method-for-existing-manufacturing/.

${ }^{13}$ Kumar, M. (2016). Lean Manufacturing And 5s Consultancy Service in Singanallur, Coimbatore, Tamil Nadu, India - Inline Solutions. Retrieved January 19, 2017, from https://www.tradeindia.com/fp996271/Lean-Manufacturing-5s-Consultancy-Service.html. 